\title{
A simplified method to estimate tidal current effects on the ocean wave power resource
}

Hashemi, M. Reza ; Grilli, Stephan T.; Neill, Simon

\section{Renewable Energy}

DOI:

10.1016/j.renene.2016.04.073

Published: 01/10/2016

Peer reviewed version

Cyswllt i'r cyhoeddiad / Link to publication

Dyfyniad o'r fersiwn a gyhoeddwyd / Citation for published version (APA):

Hashemi, M. R., Grilli, S. T., \& Neill, S. (2016). A simplified method to estimate tidal current effects on the ocean wave power resource. Renewable Energy, 96(Part A), 257-269.

https://doi.org/10.1016/j.renene.2016.04.073

\footnotetext{
Hawliau Cyffredinol / General rights

Copyright and moral rights for the publications made accessible in the public portal are retained by the authors and/or other copyright owners and it is a condition of accessing publications that users recognise and abide by the legal requirements associated with these rights.

- Users may download and print one copy of any publication from the public portal for the purpose of private study or research.

- You may not further distribute the material or use it for any profit-making activity or commercial gain

- You may freely distribute the URL identifying the publication in the public portal ?
}

Take down policy

If you believe that this document breaches copyright please contact us providing details, and we will remove access to the work immediately and investigate your claim. 
1 A simplified method to estimate tidal current effects on

\section{Abstract}

8

\author{
Rhode Island, USA \\ M. Reza Hashemi, ${ }^{\mathrm{a}, 1}$, Stéphan T. Grilli ${ }^{\mathrm{a}}$, Simon P. Neill ${ }^{\mathrm{b}}$ \\ ${ }^{b}$ School of Ocean Sciences, Bangor University, Menai Bridge, UK
}

Although ocean wave power can be significantly modified by tidal currents, resource assessments at wave energy sites generally ignore this effect, mainly due to the difficulties and high computational cost of developing coupled wave-tide models. Furthermore, validating the prediction of wave-current interaction effects in a coupled model is a challenging task, due to the paucity of observational data. Here, as an alternative to fully coupled numerical models, we present a simplified analytical method, based on linear wave theory, to estimate the influence of tidal currents on the wave power resource. The method estimates the resulting increase (or decrease) in wave height and wavelength for opposing (or following) currents, as well as quantifying the change in wave power. The method is validated by applying it to two energetic locations around the UK shelf - Pentland Firth and Bristol Channel - where wave/current interactions are significant, and for which field data are available. Results demonstrate a good accuracy of the simplified analytical approach, which can thus be used as an efficient tool for making rapid estimates of tidal effects on the wave power resource. Additionally, the method can be used to help better interpret numerical model results, as well

\footnotetext{
${ }^{1}$ Corresponding author, Submitted, Renewable Energy

Email: reza_hashemi@uri.edu
} 
as observational data.

Keywords: Wave-current interactions, Resource assessment, Wave power, Pentland Firth, Bristol Channel

\section{Introduction}

The exploitation of ocean wave power as a renewable energy resource has generated much interest in academia and industry, and has inspired many inventors, with more than one thousand patents registered to date for wave energy technologies [1]. The accurate assessment of site-specific ocean wave resource is the first step in developing projects for wave energy extraction [2].

Wave-current interactions are routinely ignored in such resource assessments (e.g. [3, 4]), despite earlier research that illustrates the significant influence of tidal currents on wave properties, such as height and wavelength $[5,6,7]$. This is partly due to the high computational cost associated with running coupled wave-tide models; also, validating wave-current iteration effects in numerical models is a challenging task due the paucity of observations and the complexity of the physical processes involved.

The effect of tidal currents on the wave power resource has been considered in a few studies to date, on the basis of coupled wave-tide models. Barbariol et al. [8] demonstrated that the inclusion of wave-current interaction (WCI) effects could yield up to a 30\% difference in wave power estimates at a location off the Gulf of Venice. The ROMS (Regional Ocean Modelling System) ocean model and SWAN (Simulating WAve Nearshore) wave model were used in coupled mode to conduct this study. Using the same mod- 
elling approach, Hashemi and Neill [9] showed that tidal currents can alter wave power by more than $10 \%$ in some regions of the northwest European shelf seas. They also briefly discussed a simple method to calculate this effect. However, in their method, they only considered the effect of tides on the wave group velocity, but on wave height, which might be greater, was ignored. Furthermore, due to this limitation, no comparison with observations was made - which could have assessed the accuracy of the method. Saruwatari et al. [10] used a coupled model (SWAN and MOHID Water Modelling System [11]) to study the effect of the WCI on the wave power, around the Orkney. They reported an up to $200 \%$ increase in wave height, when waves and currents are opposite. However, they did not demonstrate that their coupled model improved the wave simulation, in comparison to a decoupled SWAN model.

In this research, a simplified but adequately accurate and efficient analytical method is proposed to estimate the effect of tidal currents on the wave power resource. Wave power, in general, is proportional to the wave group velocity and the wave height squared (see Eq. 1); hence, WCI effects on both properties are included in the method. A limitation is that the method assumes waves are either following or opposing the currents. This assumption is valid in the majority of laboratory studies [12] and also applies in the field to many wave energy sites [13]. 


\subsection{Theoretical background}

Both wave height - which quantifies the magnitude of wave energy - and group velocity - which is the speed of wave energy transport - are modified by tidal currents. Here, we present a simple analytical method, based on linear wave theory, for estimating these changes as a function of the current velocity, when currents and waves are aligned (opposing or following). We will only consider deep water waves (or nearly), for which linear theory is a reasonable approximation. We will also assume that the current field is specified (i.e., the effect of waves on currents is neglected).

\subsubsection{Wave power in the absence of tides}

In water of depth $h$ and in the absence of a current, the period-averaged energy flux per unit width of wave crest (i.e. the mean wave power $P_{o}$ in $\mathrm{W} / \mathrm{m}$ ) is equal to the mean rate of work done by the dynamic pressure over a wave period ${ }^{2}$. According to linear wave theory, for a monochromatic wave of period $T_{o}$ and height $H_{o}$, this is given by [14],

$$
P_{o}=E_{f o}=E_{o} C_{g o}=\left\{\frac{1}{8} \rho g H_{o}^{2}\right\} C_{g o} ; \quad C_{g o}=\frac{\sigma_{o}}{k_{o}}\left\{\frac{1}{2}\left(1+\frac{2 k_{o} h}{\sinh 2 k_{o} h}\right)\right\}
$$

where $C_{g o}$ is the group velocity, $E_{o}$ is mean wave energy, $\sigma_{o}=2 \pi / T_{o}$ is the wave angular frequency, and $k_{o}=2 \pi / L_{o}$ is the wave number (with $L_{o}$ the wave length). The subscript $o$ indicates that wave properties are evaluated in

\footnotetext{
$2 \frac{1}{T} \int_{0}^{T} \int_{-h}^{\eta} p_{D} u_{w} d z d t$, where $p_{D}$ is the dynamic pressure and $u_{w}$ is the horizontal wave induced particle velocity, and $\eta$ the wave surface elevation.
} 


$$
\sigma_{0}^{2}=g k_{o} \tanh \left(k_{o} h\right)
$$

${ }_{91}$ For deep water waves, i.e., $k_{o} h \geq \pi[14], \tanh \left(k_{o} h\right) \simeq 1$ in Eq. (2) and ${ }_{92} k_{o} \simeq \sigma_{o}^{2} / g$. Hence, in Eq. (1), we have $C_{g o} \simeq g /\left(2 \sigma_{o}\right)=g T_{o} /(4 \pi)$, which 93 leads to,

$$
P_{o}=\frac{\rho g}{32 \pi} H_{o}^{2} T_{o}
$$

94 For irregular waves described by a wave energy spectrum, with significant 95 wave height $H_{s o}$ and wave energy period $T_{e o}, H_{o}$ would be replaced in Eq. 96 (3) by the root-mean-square (RMS) wave height $H_{o, R M S}$ (with, in deep water, ${ }_{97} \quad H_{o, R M S}=H_{s o} / \sqrt{2}$ ) and $T_{o}$ by an equivalent "energy" wave period $T_{e o}$ (see Ta-

ble 1 for the definition of the energy period based on a wave energy spectrum).

\subsubsection{Wave power in the presence of tidal currents}

When a monochromatic wave propagates in the presence of a tidal current of magnitude $u$ (projected in the direction of wave propagation), the wave energy flux is no longer conserved, due to energy exchange between the wave and current fields. Instead, the total period-averaged energy flux (or transport) $E_{t f}$ is conserved, which in a vertical plane comprises other terms 
such as the kinetic energy of the current ${ }^{3}$, and is given by (e.g. $[15,16]$ ),

$$
E_{t f}=\left[E C_{g}\right]+[E u]+\left[\frac{1}{2} \rho g h u^{3}\right]+\left[u\left(2 \frac{C_{g}}{C}-\frac{1}{2}\right) E\right]=\mathrm{cst}
$$

(iii)

(iv)

\footnotetext{
${ }^{3} E_{t f}=\frac{1}{T} \int_{0}^{T} \int_{-h}^{\eta}\left[p_{D}+\rho g \eta+\frac{1}{2} u \rho\left|\mathbf{u}+\mathbf{u}_{\mathbf{w}}\right|^{2}\right] u_{w} d z d t$.
}

$$
\sigma_{o}=\sigma+k u
$$
flowing/opposite current, respectively.

which as expected predicts a reduced/increased relative frequency for a co- 
The presence of additional terms in Eq. (4) introduces some difficulties in the direct application of the energy flux conservation law. For this reason, in state-of-the-art phase-averaged wave models (e.g., SWAN [17]) one instead expresses the conservation of wave action $E / \sigma[18,19]$ which, unlike the total wave energy flux, is conserved in the presence of an ambient current. In a one-dimensional case, it reads,

$$
\frac{\partial(E / \sigma)}{\partial t}+\frac{\partial\left\{\left[u(x, t)+C_{g}\right](E / \sigma)\right\}}{\partial t}=0
$$

Besides wave energy - or wave height - the wave angular frequency and wavenumber are unknown in the above equation, which requires using additional equations. Assuming linear wave theory, these are the linear dispersion relationship Eq. (2) and the conservation of wave crests equation (i.e. $\left.\frac{\partial k}{\partial t}+\frac{\partial \sigma_{o}}{\partial x}=0 ;[20,14]\right)$, which together with Eq. (5) lead to the well-posed system of equations,

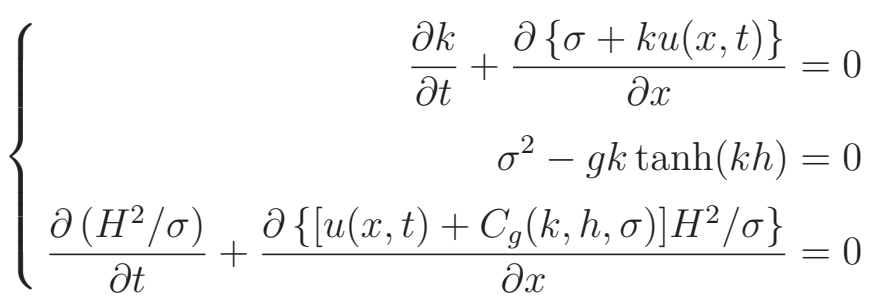

By replacing $\sigma$ from the second into the first Eq. (7), each of the above equations can be independently solved for $k, \sigma$, and $H$, respectively.

Note that, using Eq. (5), the dispersion relationship for the relative 
frequency (2nd Eq. (7)) can also be expressed as,

$$
\sigma_{o}^{2}\left\{1-\frac{u}{C}\right\}^{2}=g k \tanh (k h)
$$

where $C=\sigma_{o} / k$ is the relative wave phase speed. Given $\sigma_{o}, u$ and $h$, Eq. (8) can be solved numerically to find $k$.

\subsection{The simplified method}

Since the tidal period is much greater than the wave period, it is reasonable to assume a quasi-steady state, for which both the magnitude and direction of the tidal current can be considered as stationary with respect to the wave field, i.e., $\frac{\partial}{\partial t} \simeq 0$ in Eq. (7). Given the wave properties in the absence of a tidal current, $H_{o}$ and $\sigma_{o}$ in depth $h$, the modified properties when there is a tidal current $u$ can be found based on Eqs. (7),

1st $\rightarrow \sigma_{o}=\sqrt{g k \tanh (k h)}+k u(x)=\operatorname{cst} \rightarrow k=\checkmark$

2nd $\rightarrow \sigma=\sigma_{0}-k u(x) \rightarrow \sigma \& C_{g}=\checkmark$

3rd $\rightarrow\left[C_{g o}\right] \frac{H_{o}^{2}}{\sigma_{o}}=\left[u(x)+C_{g}\right] \frac{H^{2}}{\sigma}=\mathrm{cst} \rightarrow H / H_{o}=\checkmark$

Note that, as indicated before, $k$ can also be found by solving Eq. (8), and the 2nd Eq. (1) is used to calculate $C_{g o}$ and $C_{g}$.

\subsubsection{Deep water approximation for quasi-steady case}

The three steps described above to find wave properties in the presence of a tidal current first require solving the transcendental equation for $k$, which can easily be implemented numerically. However, a closed form relationship 
can be derived for this equation when assuming deep water waves, which as discussed before implies, $\sigma^{2} \simeq g k$ (in 2nd Eq. (7) or Eq. (8)). Solving Eq. 8 , we find [14],

$$
C=\frac{\sigma_{o}}{k}=u+\frac{C_{o}}{2}\left\{1+\sqrt{1+\frac{4 u}{C_{o}}}\right\}
$$

with $C_{o}=g / \sigma_{o}$, the wave phase speed. A deep water approximation is often valid for wind generated waves in the vicinity of wave energy devices. The range of water depths where wave energy converters are installed varies depending on the type of device; for instance, oscillatory devices are typically installed in more than a $40 \mathrm{~m}$ depth [2] and Pelamis is designed for a $50 \mathrm{~m}$ depth [21]. In practice, owing to the small slope of the tanh function near the deep water limit, the $k h \geq \pi$ requirement, which ensures a few percent errors on the linear dispersion relationship, can be somewhat extended into shallower waters. Thus, a relatively large wave with a period $T=8 \mathrm{~s}$ propagating in a $h=40 \mathrm{~m}$ water depth, has a $L=2 \pi / k=96 \mathrm{~m}$ wavelength, and thus $k h=2.52<\pi$; but for this wave, $\tanh (k h)=0.96$, and the deep water approximation estimates the wavelength at $100 \mathrm{~m}$, which is still reasonably accurate.

Based on Eq. (9) and the earlier equations simplified when assuming deep water waves, Table 2 summarizes the various closed form relationships that can be derived to express changes in wave angular frequency, power, total energy flux, and height, due to a tidal current $u$. Given the wave properties in the absence of a tidal current (e.g., obtained from a decoupled wave model), these relationships can be used to compute wave properties in the presence of a tidal current. 


\subsubsection{Discussion of limitations of the proposed method}

To reliably apply the proposed method to realistic case studies, it is necessary to clearly establish its limitations. Besides the assumptions already discussed in the above derivations, limitations in the applicability of the method result from an increase in wave nonlinearity, possibly leading to wave breaking, and from wave blocking due to opposing currents. When waves propagate into an opposing currents, their wavelength and group velocity (i.e., $u+C_{g}$ ) decrease, leading to an increase in wave height and, consequently, to steeper (and hence more nonlinear) waves; as steepness increases, waves will approach their breaking limit. Furthermore, if the current velocity is large enough, the group velocity may approach zero and waves will be "blocked" by the current [22]. More details are provided below.

\section{a Wave breaking by opposing currents}

Miche's law, which gives the breaking limit in deep water as a maximum steepness $k H_{b}$, was generalized by [23] for arbitrary depth as,

$$
\frac{k H_{b}}{\gamma \tanh k h}=1
$$

where $H_{b}$ is the breaking wave height and $\gamma$ a constant parameter known as the "breaking index". In shallow water $(\tanh k h \approx k h)$, this equation reduces to the standard depth-induced breaking limit: $H_{b} / h=\gamma($ with $\gamma \approx 0.7-0.8$ ), whereas in deep water ( $\tanh k h \approx 1)$, it is identical to Miche's law, with the recommended value $\gamma \simeq 0.6$ based on experimental data, $k H_{b}=0.60$ [22].

The increase in wave steepness as a function of an of opposing current velocity is plotted in Fig. 1, based on the equations in Section 2.2. For 
instance, an opposing current with $u / C_{o}=0.15$, approximately doubles wave steepness. Hence, for a wave of period $9 \mathrm{~s}, C_{o}=11.7 \mathrm{~m} / \mathrm{s}$ and $u=1.7 \mathrm{~m} / \mathrm{s}$ (about 3 knots); a wave with this period and a steepness $k H \simeq 0.3$ in the absence of currents will break when facing a 3 knot current.

\section{b Wave blocking by opposing currents}

For sufficiently strong currents, the propagation of wave energy will be stopped, i.e., wave blocking will occur. In deep water, the dispersion equation reads

$$
\sigma^{2}=\left(\sigma_{o}-u k\right)^{2}=g k \Rightarrow \sigma_{o}-u k=\sqrt{g k},
$$

implying that, for a given absolute frequency $\sigma_{o}$ and opposing current velocity $u$, the solution of this equation is at the intersection between a line (LHS) and a curve (RHS). Fig. 2 shows graphically the solution of the dispersion equation for three different cases, assuming waves are traveling in the $x$ direction $(k>0)$ and facing an opposing currents $u<0$ : no current, an opposing current of less than the stopping velocity, and a current equal to the stopping velocity. If the current (slope of lines) is large enough, the line becomes tangential to the curve; as this is a limiting case, no solution exists for larger velocities. This limiting velocity is referred to as the stopping velocity and corresponds to a zero group velocity, for which waves will be completely blocked by the opposing current. An expression for the stopping velocity can be derived, by specifying the "tangent" condition, $\mathrm{d} \sqrt{g k} / \mathrm{d} k=$ $-u_{s}$, in Eq. 11 as [24]

$$
u_{s}=-\frac{g}{4 \sigma_{o}}
$$


For the above example of a wave with a $9 \mathrm{~s}$ period, the stopping velocity is $3.5 \mathrm{~m} / \mathrm{s}$ (or 7 knots). Tidal currents of this strength only occur at a few specific high-energy locations suitable for tidal energy development (e.g. [25]) or in tidal inlets, but rarely exist at wave energy sites. If $|u|<u_{s}$ for the opposing current, the dispersion equation has 2 solutions (points A and B in Fig. 2), the first one (point A) representing a wave with shorter wavelength than without a current, while the second one (point B) representing very short length waves, which are reflected by the current; in both cases, wave energy is transported in the positive $x$ direction. A more detailed discussion has been provided elsewhere [24] .

\section{c Nonlinearity}

An opposing current increases wave steepness and thus nonlinearity, making waves both skewed and asymmetric (i.e., both front-to-back and trough to crest); the phase speed of strongly nonlinear waves also depends on wave height.

Spectral operational wave models, such as SWAN, which have been coupled with hydrodynamic models (e.g., ADCIRC or ROMS $[26,27])$ do not simulate such nonlinear effects and are based on linear wave theory [28]. Fully nonlinear wave-current interaction models have been developed in the time domain, but are computationally expensive and prohibitive for performing the long-term simulations required for wave energy resource assessments (e.g., [28]). Using a very similar formulation to that discussed in Section 2.1, and based on a comparison of the linear and nonlinear dispersion relationships with experimental data, Chawla and Kirby [22] showed that nonlinearity is 
only important close to the breaking or blocking points. This is confirmed in Fig. 3, which compares the linear and (3rd-order [22]) nonlinear dispersion relationships, in deep water for $H=2 \mathrm{~m}$, and shows that the linear equation is accurate up to $\sigma \simeq 1.2 \mathrm{r} / \mathrm{s}$, corresponding to $k H \simeq 0.3$; for larger steepnesses, discrepancies with the nonlinear equation gradually increase up to the breaking point. The third-order dispersion relationships for periodic Stokes waves in arbitrary depth is given by

$$
\sigma=\sqrt{g k \tanh k h\left[1+\left(k \frac{H}{2}\right)^{2}\left(\frac{8+\cosh 4 k h-2 \tanh ^{2} k h}{8 \sinh ^{4} k h}\right)\right]}
$$

which is clearly steepness dependent.

In summary, based on the above discussion, the simplified methodology proposed in this paper is only valid for moderate wave steepness $k H<<0.6$, perhaps up to $k H=0.3$, i.e., for waves that are not close to the breaking point. Additionally, the tidal current should be significantly less than the stopping velocity for the considered waves, $u \ll u_{s}$. These assumptions will be found to be often valid for the realistic sites discussed in the next sections.

\section{Field data for validating the proposed method}

The simple analytical method presented above is valid for any site where the assumptions made are realistic, i.e., linear deep water waves over a stationary current. As indicated, however, it is also hoped that the method would apply to waves that have already somewhat entered the intermediate water depth regime. This will be verified using field data. 
In the following, we assess the performance of the simplified method for two sites on the UK shelf, in which wave data was collected using wave buoys (Fig. 4) : (i) Pentland Firth, south of Orkney, and (ii) Scarweather, in the Bristol Channel. Figs. 5a,c show time series of significant wave height measured at the two sites during 15 days in March 2012 and January 2007, respectively; we see that these are fairly energetic sites, with $H_{s}$ varying between 1-4 and 1-5 m, respectively. The corresponding wave periods vary between $6 \mathrm{~s}$ and $10 \mathrm{~s}$ for these time series. Fig. 6 shows typical wave fields, in the form of average significant wave heights and direction, computed around the two selected sites using the SWAN wind-wave model, during the periods of field data collection at the buoys. The SWAN model and its set-up have been described in $[3,9]$. We see that the prevailing wave direction is eastward around both sites.

Representative time series of tidal current velocity were simulated around the two selected sites using the ROMS model. A detailed description of tide modeling has been presented elsewhere [25, 9], and Table 3 gives the ROMS model configuration at the two selected sites. Fig. 7 shows the tidal ellipses computed at each site based on theses simulations; we see that the dominant current direction is approximately east-west at each site. Hence, it is reasonable to assume that waves are almost aligned with the tidal currents at both locations.

As a results of the energetic wave conditions and strong tidal currents, in recent years, the Orkney archipelago has attracted much attention for wave and tide energy development. The establishment of the European Marine Energy Center (EMEC) in Orkney was a key step towards the development of 
wave power harvesting, together with ambitious plans for developing 1.6 GW of marine renewable energy by 2020, in this region [29]. Although the wave energy resource of the Bristol Channel is less than that of Orkney [30], some wave energy devices have been tested in this area. Furthermore, due to the presence of strong tidal currents, a number of researchers have shown some interest in studying wave-tide interactions in both regions [10, 31, 32, 33].

\subsection{Frequency and time domain analysis}

Astronomical tides have predetermined periods, which are controlled by the relative motion of the Earth-Moon-Sun system. Therefore, waves that have been strongly affected by tides should show signs of modulations at the periods associated with astronomical tides. The principal lunar (M2) and solar (S2) semidiurnal constituents, with periods of $12.42 \mathrm{hr}$ and $12.00 \mathrm{hr}$, respectively, are the most important tidal components around the sites of interest [34]. As an example, Fig. 8a shows an idealized signal, which has been modulated by tides resulting from M2, S2, and M4 constituents. The M4 super-harmonic tidal component - with a period of $6.41 \mathrm{hr}$ - has made the modulation slightly asymmetric [25]. This time series can be decomposed into two signals as follows,

$$
f(t)=f_{o}(t)+f_{\text {Tide }}(t)
$$

where $f_{o}$ is the signal in the absence of tides and $f_{\text {Tide }}$ results from the tidal effects. One way to separate and evaluate the tidal effects is to transform the time series to the frequency domain using a fast Fourier transform (FFT, $[35,36])$. This is done in Fig. $8 \mathrm{~b}$, where we see that the magnitude and 
period of each tidal constituent's effect can be separated using this method. After transforming the signal to the frequency domain, tidal effects could be removed by passing the signal through a band-stop or notch filter [36] and applying an inverse FFT. This procedure will be applied to data measured at both sites, to identify tidal current effects on wave properties and compare results with those of the proposed simplified method. Note, this method has limitations, as it is assumed that the two signals are linearly superimposed and nonlinear interactions can be ignored.

Thus, the procedure was applied to the time series of significant wave height collected at both field sites (Figs. 5a,c). Figs. 5b,d shows both signals transformed in the frequency domain, where we clearly see the effect of the M2 tidal component on the wave height, with a period of $12.42 \mathrm{hr}$.

\section{Results}

In Fig. 9, we computed the ratio of wave properties in the presence and absence of a tidal current, using the simplified method described in Section 2.2 and summarized in Table 2 , for a range of wave periods $T$ and current velocities $u$. This figure also demonstrates that using the complete equations (i.e. Section 2.2) does not lead to a significant difference. Results were calculated for a nominal $40 \mathrm{~m}$ water depth, assuming deep water conditions; however, using the complete equations, it can be shown, that these are not very sensitive to the water depth for this range of wave parameters.

In Fig. 9, we see that, as expected, wave height increases/decreases for an opposing/following current, respectively. In the former case, this effect is magnified for the (relative) wave power, which is proportional to the square 
of wave height. The amplification is less for the wave energy flux - or the absolute wave power observed by a stationary observer - since opposing currents, in general, slow down the transport velocity of wave energy. In Fig. 9a, the power amplification factor collapses onto a single curve when the current velocity is normalized by wave celerity; but, in Fig. 9b it varies for different wave periods, as a function of the current velocity. For instance, $u=-2 \mathrm{~m} / \mathrm{s}$ corresponds to three values of $u / C_{0}=2 \pi u /(g T)=0.14,0.16$ and 0.18 in other subplots, corresponding to wave periods of 7,8 and 9 seconds; therefore, three different values of $P / P_{o}$ also correspond to $u=-2 \mathrm{~m} / \mathrm{s}$. For co-flowing currents, wave height decreases, while the wave energy propagation velocity increases (i.e. $C_{g}+u$ ). The former has more effect on the wave energy flux than the latter, which leads it to decrease. For a site with an opposing current velocity of about $1.5 \mathrm{~m} / \mathrm{s}$, wave power increased by up to $100 \%$ (or $60 \%$ in wave height), and the effect is even more pronounced for lower energy (shorter period) waves. The increased effect of tides in regions with lower wave energy has been reported in other research $[8,9]$.

The accuracy of these predictions was first assessed for the Pentland Firth site. Fig. 10a shows a subset of the time series of significant wave height measured at this site (Fig. 5). As mentioned before, for irregular waves, the equations derived for the simplified method assuming monochromatic waves can be used by replacing $H$ by $H_{R M S}$, which is proportional to $H_{s}$; hence, $H / H_{o} \rightarrow H_{R M S} / H_{o, R M S}=H_{s} / H_{o s}$. Using the observed time series of $H_{s}$ values in Fig. 10a, the tidal modulation was filtered out, as detailed in Section 3.1, and the remaining signal was treated as the significant wave height in the absence of tides, $H_{o s}$; the ratio of wave height in the presence 
and the absence of tides, $H / H_{o}=H_{s} / H_{o s}$, was then calculated. The time series of this ratio is plotted in Fig. 10b and compared to that predicted by the simplified method, based on tidal current velocities estimated from the tidal ellipses (Fig. 7) computed at the site (Fig. 10c). Considering in Fig. 10 a time period during which the significant wave height was relatively large (more than $1 \mathrm{~m}$; marked by vertical lines), we see in Fig. 10b that, despite the many assumptions behind the simplified method, it can accurately capture both the frequency and magnitude of the tidal modulation.

This is confirmed in Fig. 11, which shows a comparison in the frequency domain of wave height ratios (i.e., $H / H_{o}=H_{s} / H_{o s}$ observed for irregular waves; Fig. 10) at the Pentland Firth site to those predicted using the simplified method, with and without tidal current. In Fig. 10a, we see that the observed time series of $H_{s} / H_{o s}$ is approximately a harmonic function of amplitude 0.1, oscillating around 1.0, with a period of about $12.41 \mathrm{hr}$ (i.e. $y(t)=1+0.1 \sin 2 \pi / 12.41 t$ ). This is clearer in Fig. 11 where we see, after performing a Fourier transform, that the simplified method predicts the period and amplitude of the modulations of the observed wave height ratio within $2 \%$, confirming its predictive ability near the M2 principal tidal constituent period, which dominates tidal effects at the selected study sites. The same analysis was repeated for the Scarweather site. Results are reported in Figs 12 and 13, which demonstrate a level of accuracy similar to that of the Pentland Firth site (i.e. less than $2 \%$ error for period and amplitude of the modulation in Fig. 13). 
5. Discussion

Besides the assumptions introduced in Section 2.1, other considerations should be taken into account when applying the simplified method. The effect of tidal elevation variations was ignored, as it was previously shown (using coupled models), that this parameter has much less effect on wave power than currents [9]. Assuming linear wave theory also implies that the actual sea state is approximated by a superposition of harmonic waves, in which no sinks or sources of energy interact with the wave field. This assumption would not lead to a significant error, since the method is only locally applied to a wave field, which has already been generated by proper sources and sinks of energy, and faces a current field.

A model such as SWAN can include effects of the ambient current field in the wave simulation. However, special care should be taken to extract and interpret the wave power predicted in these models in the presence of currents. For instance, SWAN's output variable 'TRANSP' (Energy transport), which is often used to evaluate the wave power, actually represents the relative wave power (i.e. $\int C_{g} E d \sigma[37]$ ). The wave energy transport, or absolute wave power, is $\int\left(C_{g}+u\right) E d \sigma$ (Eq. 4), which, to the best of the authors' knowledge, is not available as an output variable.

Assessing the wave resource at a specific site involves two steps; characterizing, (1) the theoretical wave energy resource, and (2) the technical wave energy resource. The extractable power $P_{\text {Tech }}$ (i.e., the technical power) from a wave energy converter is a function of wave height and period at a site (i.e., theoretical wave energy resource), and of the efficiency of the device. This 
can be expressed as

$$
P_{\text {Tech }}=f\left(H_{s}, T_{e}\right)=C_{p}\left(H_{s}, T_{e}\right) E_{f}\left(H_{s}, T_{e}\right)
$$

where $f$ denotes a function (i.e., power matrix), which implicitly includes the efficiency of the device, $C_{p}$ is the power coefficient, and $E_{f}$ the theoretical wave power or total wave energy flux at the studied location. To perform theoretical resource assessments, three methods are usually used. The first one estimates wave power using an uncoupled wave model (e.g., SWAN) that ignores tidal effects. For such a case, this paper provides a method by which the effects of tidal modulations can be superimposed on time series of wave height predicted by the uncoupled model. The second method is to use observed data (e.g., collected at a wave buoy), in which the effects of tide on the wave resource are implicitly included. In this case, the methodology presented in this paper can be used to clearly identify the tide-induced modulations/contributions in/to the wave power. More importantly, the proposed methods can help generalize such effects to longer time series for which there are no observed data. Rarely, a third method consisting in applying fully coupled wave-tide models may be used for wave resource assessment, and in this case the proposed analytical/simplified methods can provide insight into model results and their interpretations.

Finally, note that in terms of technical resource assessment, this research does not investigate the possible effects of wave-tide interactions on power curves, which are device-dependent and hence cannot be generalized to all devices. However, it helps provide better estimates of technical power by performing a more accurate assessment of wave height at a site that is influenced 
by tides (theoretical resource).

As mentioned before, opposing and following currents lead to an increase or decrease in wave height, respectively. However, this effect is highly asymmetrical for the wave height and other quantities related to wave energy, for each current direction (Fig. 9). To further analyze the practical implications of this observation, we considered a single Pelamis device, rated at $750 \mathrm{~kW}$, whose power matrix is plotted in Fig. 14, for multiple combinations of significant wave height and period [38]. It can be inferred from this matrix that for a constant wave period - the modulation of wave height by a tidal current can lead to significant variations in wave power output of the device, while for a constant wave height, the wave power is less sensitive to a small variations in the wave period. Fig. 15 shows an idealized case for which overall effects of tidal currents on the technical wave power that can be extracted from a device has been examined. For simplicity a constant wave period of 9 s was considered in Fig. 15a. It is clear from Fig. 15c that the overall effects of the current is an increase of wave energy. For this case, the integral of the wave power time series over a 15 day period is 89.9 MWh and 95.2 MWh in the absence and presence of a tidal current, respectively. One should caution, however, while tidal currents can increase the extractable wave power, they may lead to difficulties in the operation of wave energy devices, and consequently reduced efficiency.

\section{Conclusions}

We presented a simplified method, based on linear wave theory, which can be used to predict the effects of tidal currents on the wave power resource. 
The method demonstrates that one can expect a significant increase in wave height and power when currents are opposing waves (e.g., a $60 \%$ increase in wave height for a $-2.0 \mathrm{~m} / \mathrm{s}$ current and a $8 \mathrm{~s}$ wave period), and a decrease in these quantities, albeit smaller, when waves are following the currents (e.g., a $20 \%$ decrease in wave height for a $+2.0 \mathrm{~m} / \mathrm{s}$ current and a $8 \mathrm{~s}$ wave period). Because of this asymmetrical effect of a current on wave properties, the net effect of a symmetrical tidal current is an increase of the wave energy at a given location; hence, in this case, the overall extractable wave energy by a device also increases.

The accuracy of the simplified method was shown to be adequate for two field sites of interest, by comparing results with observed data. It was assumed that waves and currents are approximately aligned with each other, which is valid in the selected wave energy sites, and others, and in most laboratory studies of wave-current interaction.

At a wave energy site where currents are significant, energy transfer components such as the kinetic energy of currents, energy exchange between currents and waves, relative wave power, and total wave energy transfer should be carefully considered to realistically assess the technically extractable wave energy resource. It should be noted that the presence of tidal currents may reduce the performance of a tidal energy converter if it was designed assuming no flow conditions.

\section{Acknowledgements}

Thanks to Cefas WaveNet for supplying the wave buoy data at Scarweather, and to Philippe Gleizon (University of the Highlands and Islands, 
479 Thurso) for providing wave buoy data at Pentland Firth. S.P. Neill ac480 knowledges financial support provided by the Welsh Government and Higher 481 Education Funding Council for Wales through Sêr Cymru National Research 482 Network for Low Carbon Energy and the Environment 


\section{References}

[1] M. E. McCormick, Ocean wave energy conversion, Courier Corporation, 2013.

[2] F. d. O. Antonio, Wave energy utilization: A review of the technologies, Renewable and sustainable energy reviews 14 (2010) 899-918.

[3] S. P. Neill, M. J. Lewis, M. R. Hashemi, E. Slater, J. Lawrence, S. A. Spall, Inter-annual and inter-seasonal variability of the orkney wave power resource, Applied Energy 132 (2014) 339-348.

[4] ABPmer, Atlas of UK marine renewable energy resources, Technical Report, Department for Business Enterprise \& Regulatory Reform, 2008.

[5] R. Soulsby, L. Hamm, G. Klopman, D. Myrhaug, R. Simons, G. Thomas, Wave-current interaction within and outside the bottom boundary layer, Coastal engineering 21 (1993) 41-69.

[6] N. Guillou, G. Chapalain, Modeling the tide-induced modulation of wave height in the outer seine estuary, Journal of Coastal Research 28 (2012) 613-623.

[7] J. M. Brown, A. G. Davies, Methods for medium-term prediction of the net sediment transport by waves and currents in complex coastal regions, Continental Shelf Research 29 (2009) 1502-1514.

[8] F. Barbariol, A. Benetazzo, S. Carniel, M. Sclavo, Improving the assessment of wave energy resources by means of coupled wave-ocean numerical modeling, Renewable Energy 60 (2013) 462-471. 
[9] M. R. Hashemi, S. P. Neill, The role of tides in shelf-scale simulations of the wave energy resource, Renewable Energy 69 (2014) 300-310.

[10] A. Saruwatari, D. M. Ingram, L. Cradden, Wave-current interaction effects on marine energy converters, Ocean Engineering 73 (2013) 106118.

[11] F. Maerins, P. Leitão, A. Silva, R. Neves, 3D modelling in the Sado estuary using a new generic vertical discretization approach, Oceanologica Acta 24 (2001) 51-62.

[12] N. Barltrop, K. Varyani, A. Grant, D. Clelland, X. Pham, Wave-current interactions in marine current turbines, Proceedings of the Institution of Mechanical Engineers, Part M: Journal of Engineering for the Maritime Environment 220 (2006) 195-203.

[13] M. Lewis, S. Neill, M. Hashemi, Realistic wave conditions and their influence on quantifying the tidal stream energy resource, Applied Energy 136 (2014) 495-508.

[14] R. A. Dalrymple, R. G. Dean, Water wave mechanics for engineers and scientists, Prentice-Hall, 1991.

[15] M. S. Longuet-Higgins, R. Stewart, Changes in the form of short gravity waves on long waves and tidal currents, Journal of Fluid Mechanics 8 (1960) 565-583.

[16] G. B. Whitham, Linear and nonlinear waves, volume 42, John Wiley \& Sons, 2011. 
[17] N. Booij, R. Ris, L. H. Holthuijsen, A third-generation wave model for coastal regions: 1. Model description and validation, Journal of Geophysical Research: Oceans 104 (1999) 7649-7666.

[18] G. Whitham, A general approach to linear and non-linear dispersive waves using a lagrangian, Journal of Fluid Mechanics 22 (1965) 273283.

[19] F. P. Bretherton, C. J. Garrett, Wavetrains in inhomogeneous moving media, Proceedings of the Royal Society of London. Series A. Mathematical and Physical Sciences 302 (1968) 529-554.

[20] L. H. Holthuijsen, Waves in oceanic and coastal waters, Cambridge University Press, 2007.

[21] B. Drew, A. Plummer, M. N. Sahinkaya, A review of wave energy converter technology, Proceedings of the Institution of Mechanical Engineers, Part A: Journal of Power and Energy 223 (2009) 887-902.

[22] A. Chawla, J. T. Kirby, Monochromatic and random wave breaking at blocking points, Journal of Geophysical Research: Oceans 107 (2002).

[23] J.-F. Filipot, F. Ardhuin, A. V. Babanin, A unified deep-to-shallow water wave-breaking probability parameterization, Journal of Geophysical Research: Oceans 115 (2010).

[24] R. Moreira, D. Peregrine, Nonlinear interactions between deep-water waves and currents, Journal of Fluid Mechanics 691 (2012) 1-25. 
[25] S. P. Neill, M. R. Hashemi, M. J. Lewis, The role of tidal asymmetry in characterizing the tidal energy resource of Orkney, Renewable Energy 68 (2014) 337-350.

[26] J. C. Dietrich, J. Westerink, A. Kennedy, J. Smith, R. Jensen, M. Zijlema, L. Holthuijsen, C. Dawson, R. Luettich Jr, M. Powell, et al., Hurricane gustav (2008) waves and storm surge: hindcast, synoptic analysis, and validation in southern louisiana, Monthly Weather Review 139 (2011) 2488-2522.

[27] J. C. Warner, B. Armstrong, R. He, J. B. Zambon, Development of a coupled ocean-atmosphere-wave-sediment transport (coawst) modeling system, Ocean modelling 35 (2010) 230-244.

[28] S. Ryu, M. Kim, P. J. Lynett, Fully nonlinear wave-current interactions and kinematics by a bem-based numerical wave tank, Computational mechanics 32 (2003) 336-346.

[29] G. Allan, P. Lecca, P. McGregor, J. Swales, The economic impacts of marine energy developments: A case study from scotland, Marine Policy 43 (2014) 122-131.

[30] S. P. Neill, M. R. Hashemi, Wave power variability over the northwest European shelf seas, Applied Energy 106 (2013) 31-46.

[31] J. Wolf, D. Prandle, Some observations of wave-current interaction, Coastal Engineering 37 (1999) 471-485.

[32] J. Wolf, Coastal flooding: impacts of coupled wave-surge-tide models, Natural Hazards 49 (2009) 241-260. 
[33] B. Jones, A numerical study of wave refraction in shallow tidal waters, Estuarine, Coastal and Shelf Science 51 (2000) 331-347.

[34] M. Hashemi, S. Neill, A. Davies, A numerical study of wave and current fields around Ramsey island - tidal energy resource assessment, in: XIXth TELEMAC-MASCARET User Conference, Oxford, United Kingdom.

[35] C. Van Loan, Computational frameworks for the fast Fourier transform, volume 10, Siam, 1992.

[36] T. P. Krauss, L. Shure, J. N. Little, Signal processing toolbox for use with matlab (1994).

[37] N. Booij, I. Haagsma, L. Holthuijsen, A. Kieftenburg, R. Ris, A. Van Der Westhuysen, M. Zijlema, Swan cycle iii version 40.41 user manual, Delft University of Technology 115 (2004).

[38] E. B. Mackay, A. S. Bahaj, P. G. Challenor, Uncertainty in wave energy resource assessment. part 2: variability and predictability, Renewable energy 35 (2010) 1809-1819.

[39] D. Mollison, Wave climate and the wave power resource, in: Hydrodynamics of Ocean Wave-Energy Utilization, Springer, 1986, pp. 133-156.

[40] K. Gunn, C. Stock-Williams, Quantifying the global wave power resource, Renewable Energy 44 (2012) 296-304. 
Table 1: List of symbols

\begin{tabular}{|c|c|}
\hline Symbol & Description \\
\hline$C$ & wave celerity or phase speed \\
\hline$C_{g}$ & wave group velocity \\
\hline$E$ & period-averaged wave energy: $E=\frac{1}{8} \rho g H^{2}$ \\
\hline$E_{f}$ & $\begin{array}{l}\text { period-averaged wave energy flux: transport of wave energy by group and current velocity: } \\
E=C_{g} E+u E\end{array}$ \\
\hline$h$ & water depth \\
\hline$H, H_{o}$ & wave height in the presence and absence of a current, respectively $\ddagger$ \\
\hline$H_{R M S}, H_{s}$ & RMS and significant wave height \\
\hline$H_{b}$ & wave height at the breaking point \\
\hline$k$ & wave number \\
\hline$N$ & wave action: $N=E / \sigma$ \\
\hline$p_{D}$ & dynamic pressure resulting from a linear wave \\
\hline$P$ & relative wave power: transport of wave energy by group velocity $P=C_{g} E$ \\
\hline$P_{\text {Tech }}$ & Technical wave power \\
\hline$T$ & wave period \\
\hline$T_{e}$ & energy wave period, $2 \pi m_{-1} / m_{0}$, where $m$ shows the moment of the wave spectrum [39]. \\
\hline $\begin{array}{l}T_{M 2}, T_{S 2}, T_{M_{4}} \\
u\end{array}$ & $\begin{array}{l}\text { period of } M_{2}, S_{2} \text {, and } M_{4} \text { astronomical tide components: } 12.42 \mathrm{hr}, 12.00 \mathrm{hr} \text {, and } 6.21 \mathrm{hr} \text {. } \\
\text { tidal current velocity }\end{array}$ \\
\hline$u_{s}$ & stopping velocity \\
\hline$u_{w}$ & horizontal wave induced velocity \\
\hline $\mathbf{u}_{\mathbf{w}}$ & wave induced velocity vector \\
\hline$\eta$ & water surface elevation \\
\hline$\rho$ & water density \\
\hline$\sigma$ & intrinsic or relative wave frequency \\
\hline$\sigma_{o}$ & absolute wave frequency: $\sigma_{o}=\sigma+k u$ \\
\hline$\gamma$ & breaking index \\
\hline
\end{tabular}

$\ddagger$ the $o$ subscript for all wave properties means these are in the absence of a current (e.g. $\left.k_{o}, \sigma_{o}\right)$. 
Table 2: Change of wave properties as a result of a tidal current $u$, assuming deep water waves $(k h>\pi)$

\begin{tabular}{|l|c|}
\hline Wave property & Equation \\
\hline wave frequency & $\frac{\sigma}{\sigma_{o}}=2\left[1+\sqrt{1+\frac{4 u}{C_{o}}}\right]^{-1} ; C_{o}=\frac{g}{\sigma_{o}}$ \\
(relative) wave power & $\frac{P}{P_{o}}=\frac{E C_{g}}{E_{o} C_{g o}}=\frac{\sigma}{\sigma_{o}}\left[\frac{1}{1+\frac{2 u}{C_{o}} \frac{\sigma}{\sigma_{o}}}\right]$ \\
total wave energy flux & $\frac{E_{f}}{E_{f o}}=\frac{\left(C_{g}+u\right) E}{C_{g o} E_{o}}=\frac{\sigma}{\sigma_{o}}$ \\
wave height & $\frac{H}{H_{o}}=\frac{\sigma}{\sigma_{o}}\left[\frac{1}{1+\frac{2 u}{C_{o}} \frac{\sigma}{\sigma_{o}}}\right]^{\frac{1}{2}}$ \\
\hline
\end{tabular}

Table 3: ROMS model set-up used for simulating time series of tidal currents at two sites (Fig. 4).

\begin{tabular}{|c|c|c|}
\hline & \multicolumn{2}{|c|}{ Region } \\
\hline ROMS Setting & Pentland Firth & Bristol Channel \\
\hline Horizontal resolution & $500 \mathrm{~m}$ & $5000 \mathrm{~m}$ \\
\hline Number of vertical layers & 10 & 11 \\
\hline Bathymetry & $\begin{array}{l}\text { GEBCO (www.gebco.net) and } \\
\text { data provided by St. Andrew's } \\
\text { University }\end{array}$ & ETOPO (www.ngdc.noaa.gov) \\
\hline Tidal forcing at the boundaries & $\begin{array}{l}\text { FES2012 } \\
\text { (www.aviso.altimetry.fr) }\end{array}$ & $\begin{array}{l}\text { TPXO7 } \\
\text { (volkov.oce.orst.edu/tides/) }\end{array}$ \\
\hline Tidal constituents & M2 and S2 & M2, S2 and 8 other component \\
\hline Drag coefficient & 0.003 & 0.0025 \\
\hline Turbulence model & $\mathrm{k}-\epsilon$ & $\mathrm{k}-\epsilon$ \\
\hline Validation points & $\begin{array}{l}\text { Tidal stations around Orkney } \\
\text { from the Admiralty tide tables }\end{array}$ & $\begin{array}{l}\text { Tidal stations in the Bristol Chan- } \\
\text { nel from the Admiralty tide tables }\end{array}$ \\
\hline Accuracy & $8 \mathrm{~cm}$ for $\mathrm{M} 2$ and $4 \mathrm{~cm}$ for $\mathrm{S} 2$ & $13 \mathrm{~cm}$ for $\mathrm{M} 2$ and $7 \mathrm{~cm}$ for $\mathrm{S} 2$ \\
\hline
\end{tabular}




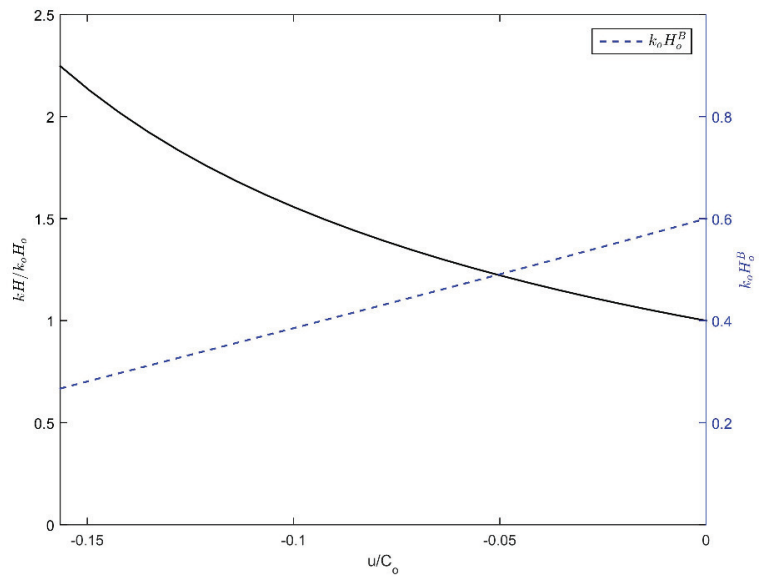

Figure 1: Effect of an opposing current velocity on periodic wave steepness and steepnessinduced breaking. The solid curve shows the increase in steepness as a function of current velocity (left axis), and the dashed line shows the threshold for wave breaking (right axis; based on the value of wave steepness without a current).

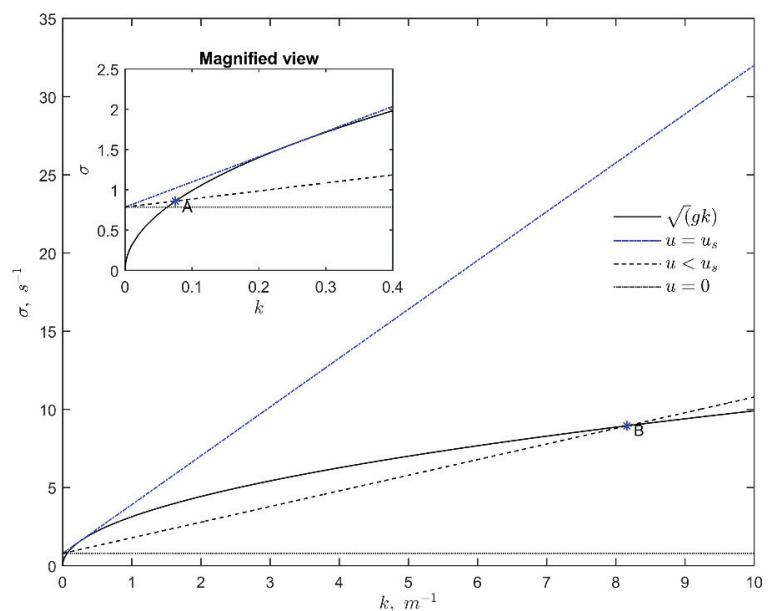

Figure 2: Graphical solution of the linear dispersion relationship, assuming no current (dotted line), an opposing current of less than the stopping velocity $u_{s}$ (dash line), and a current velocity equal to the stopping velocity (dash-dot line). The solution is at the intersections of the line (i.e., $\sigma_{o}-u k$ ) and the curve (i.e., $\sqrt{g k}$ ) (e.g., points $\mathrm{A}$ and $\mathrm{B}$ ). 


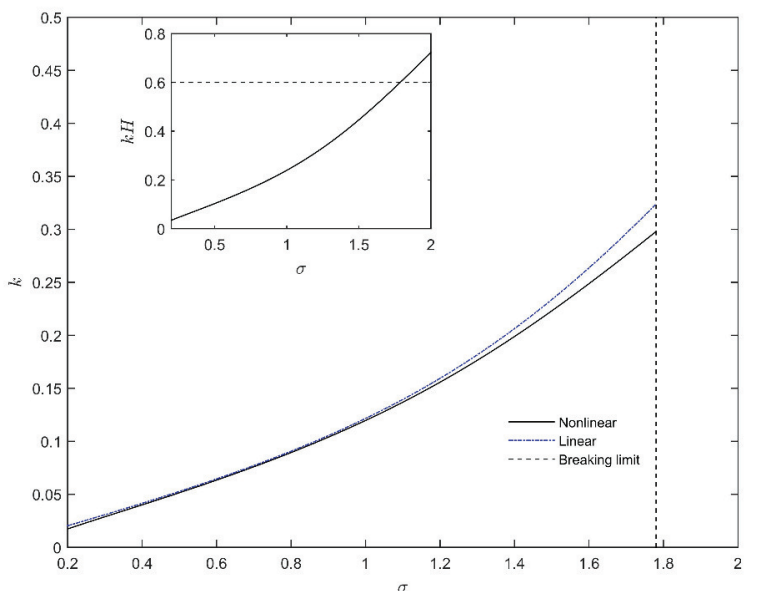

Figure 3: Nonlinear (3rd-order) and linear dispersion relationships for Stokes waves of $H=2 \mathrm{~m}$ in deep water. 


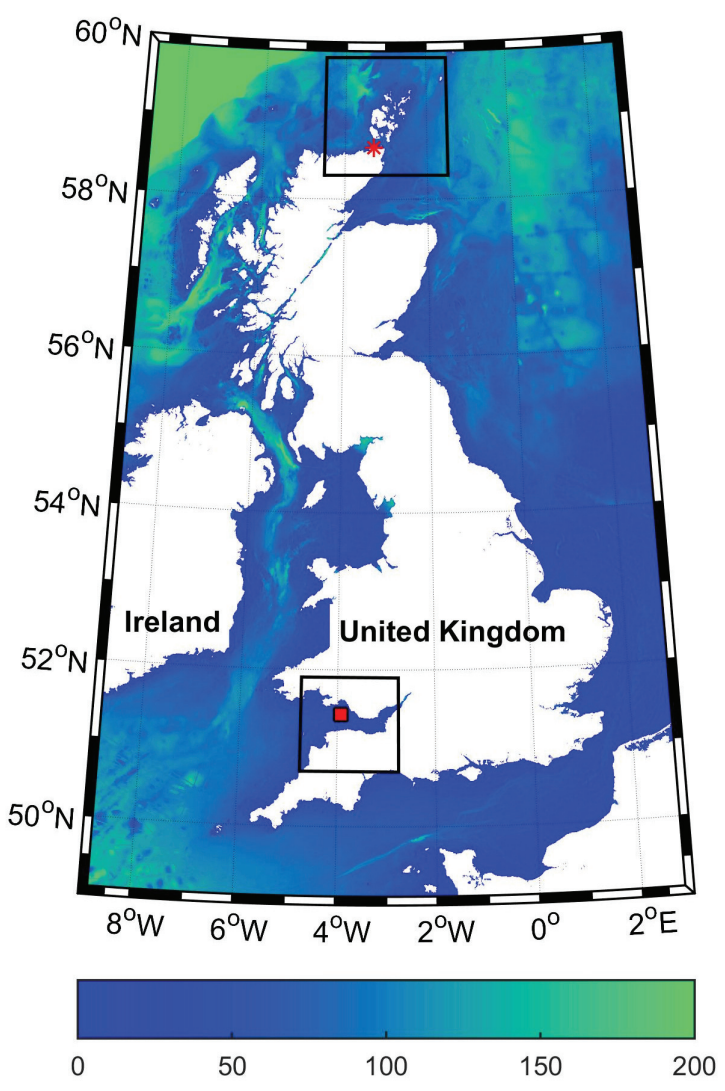

Figure 4: Locations of selected wave buoys for evaluation of wave resource assessment using the simplified method based on field data. The Pentland Firth and Scarweather measurement locations are marked by $*$ and $\square$ symbols, respectively. The average wave climates around these locations - for the period of the analysis - are plotted in Fig. 6, where the rectangles show the extent of the magnified views. Colour scale is bathymetry in meters. 
(a) Pentland Firth, time domain

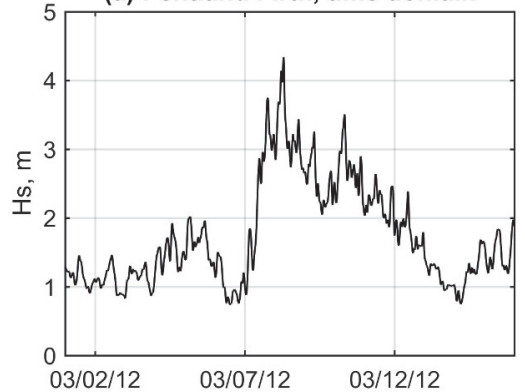

(c) Scarweather, time domain

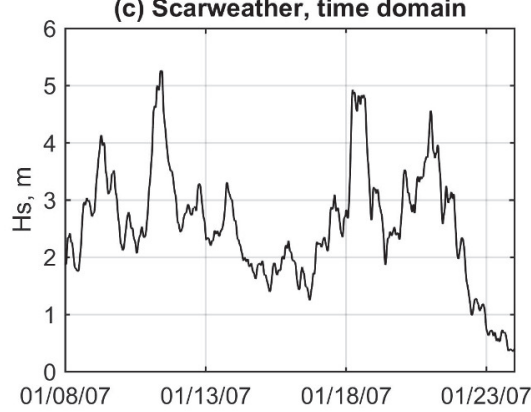

(b) Pentland Firth, frequency domain

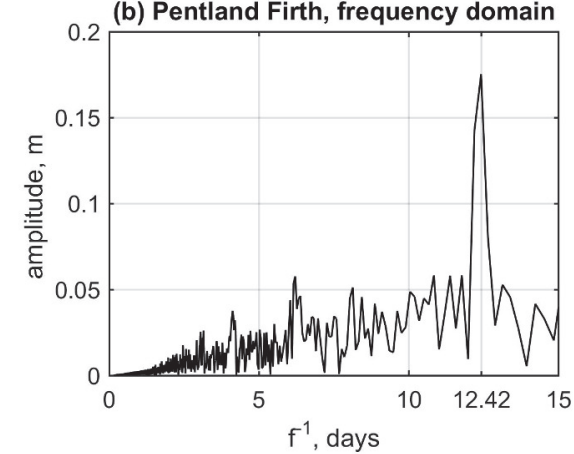

(d) Scarweather, frequency domain

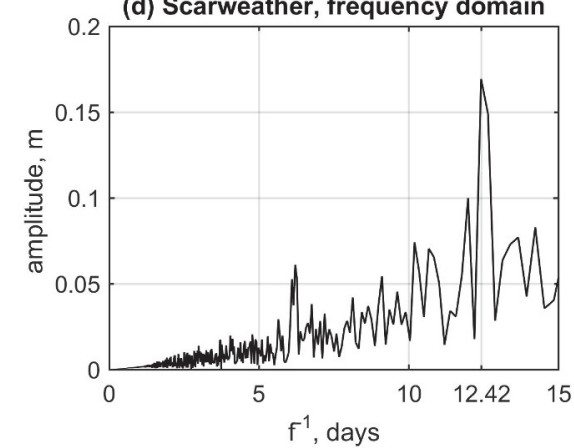

Figure 5: Time series of significant wave height, $H_{s}$ measured at the Pentland Firth and Scarweather sites (Fig. 4) in March 2012 and January 2007, respectively, during 15 days, which covers a spring-neap cycle (panels a and c). Panels b and d show Fourier transforms of the wave height time series; a clear semidiurnal tidal effect can be observed in the signal at both sites, with the period of the M2 tidal constituent. 


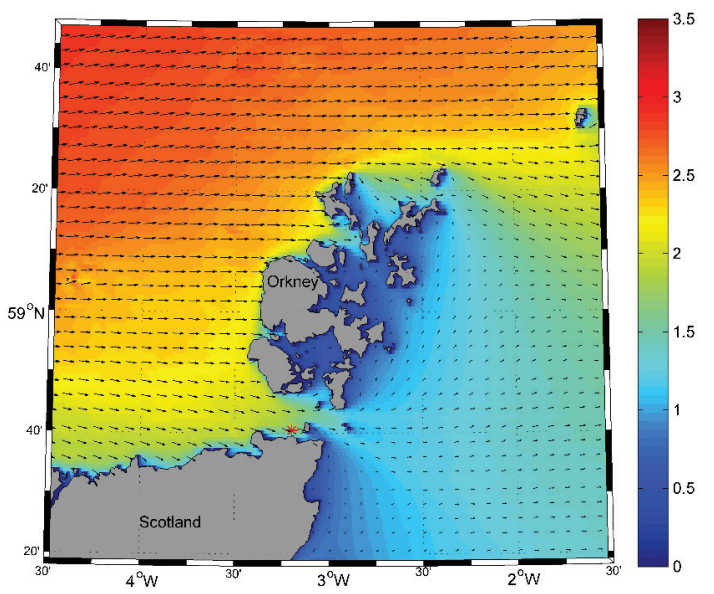

(a) Pentland Firth

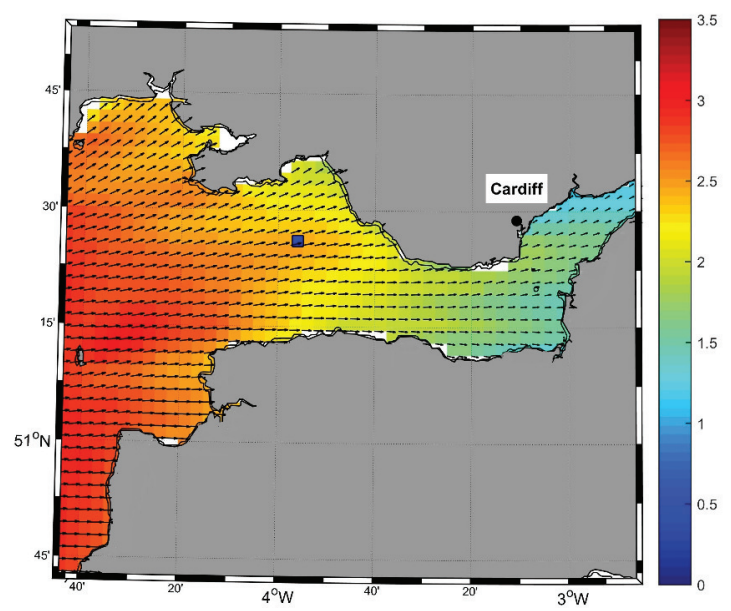

(b) Scarweather

Figure 6: Mean wave directions around the locations of interest, Pentland Firth and Scarweather sites (Fig. 4), in March 2012 and January 2007, respectively, corresponding to the availability of wave data. The dominant wave directions for these sites follow a very similar pattern in energetic months (i.e., December, January, February and March $[30,3])$. The color scales show the average significant wave height $H_{s}$ in meter for these time periods. 
(a) Pentland Firth Site

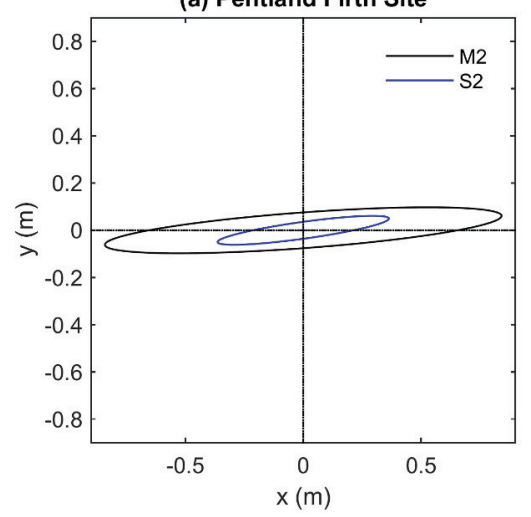

(b) Scarweather Site

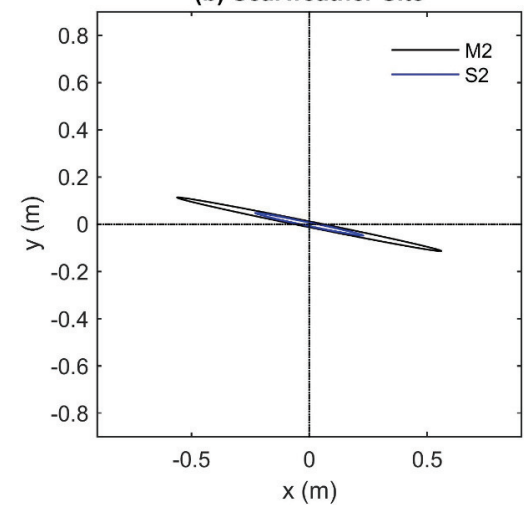

Figure 7: Tidal ellipses for Pentland Firth and Scarweather sites. The tidal currents are generally aligned east-west for both sites. 
(a) time domain

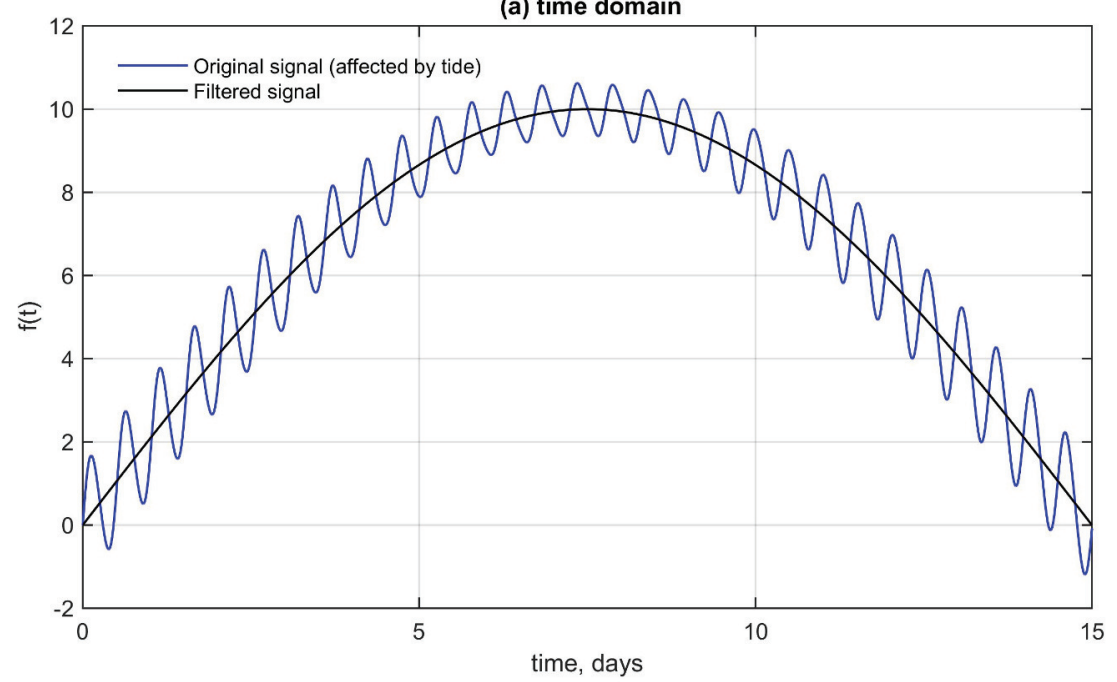

(b) frequency domain

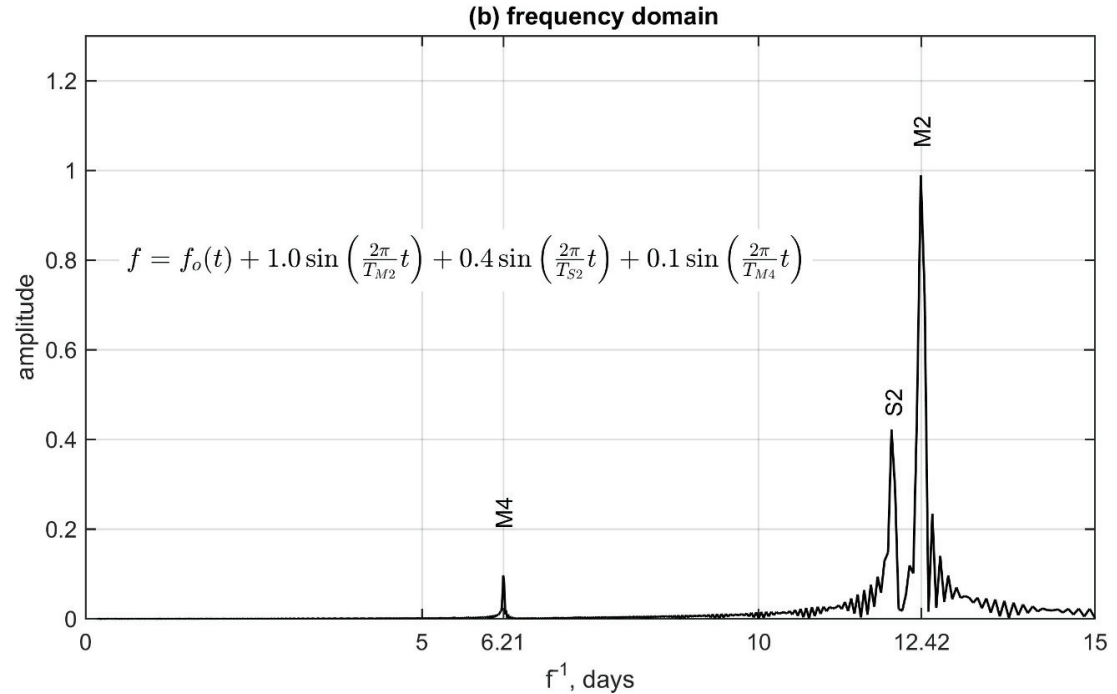

Figure 8: Typical time series with modulation caused by M2, S2, and M4 components: (a) in the time domain, and (b) in the frequency domain. 

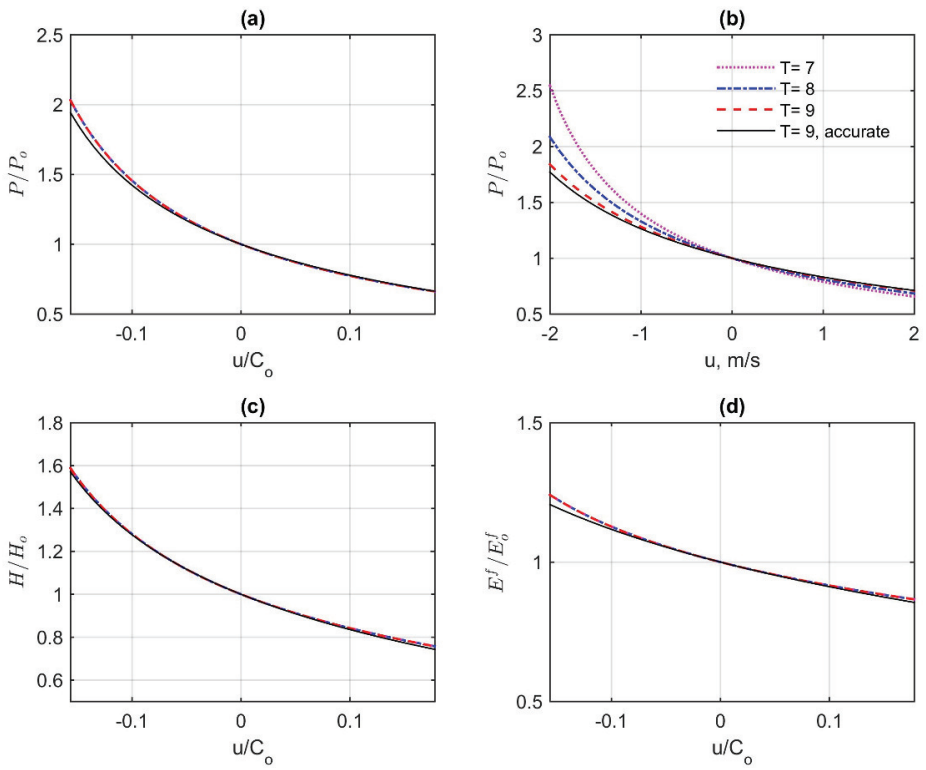

Figure 9: Effects of tidal currents on wave height and power for various wave periods. These linearized results are valid for $k H \ll 0.6$ (see Fig. 1) and $u \ll u_{s}$ (Eq. 12); subplots $\mathrm{a}$ and $\mathrm{b}$ show the effect on (relative) wave power, subplot $\mathrm{c}$ wave height, and subplot $\mathrm{d}$ wave energy flux. The wave properties - in the presence of tidal currents - have been normalized with the corresponding wave-only case. The accurate solutions (for $T=9$ ) have been evaluated using the complete equations described in Section 2.2. 

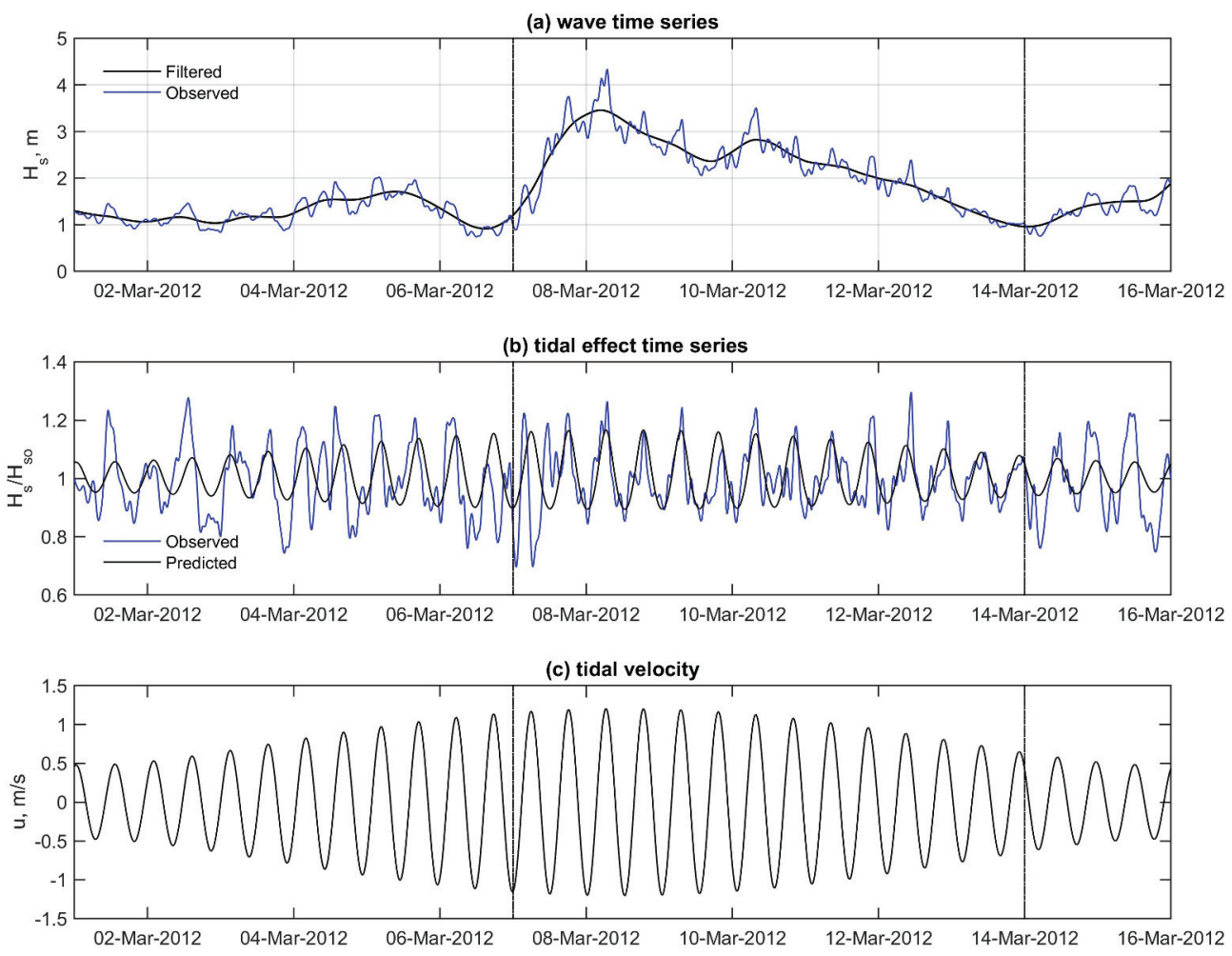

Figure 10: Estimation of tidal current effects using the simplified method for a time series of significant wave height observed at the Pentland Firth site (Fig. 4) during a spring-neap cycle. The tide-induced wave height modulations were filtered out from the signal (panel a), and the resulting wave height ratio compared with the predicted values (panel b; $\mathrm{H} / \mathrm{H}_{\mathrm{o}}$ is the ratio of wave heights in the presence and absence of a tidal current computed from the two curves in panel a). The tidal current velocity estimated with ROMS is plotted in panel c. The vertical lines mark a time interval during which wave height was relatively large $\left(H_{\mathrm{s}}>1 \mathrm{~m}\right)$, and in panel b the simplified method (predicted curve) provides a good prediction of the tidal-induced modulations, both in magnitude and frequency. 


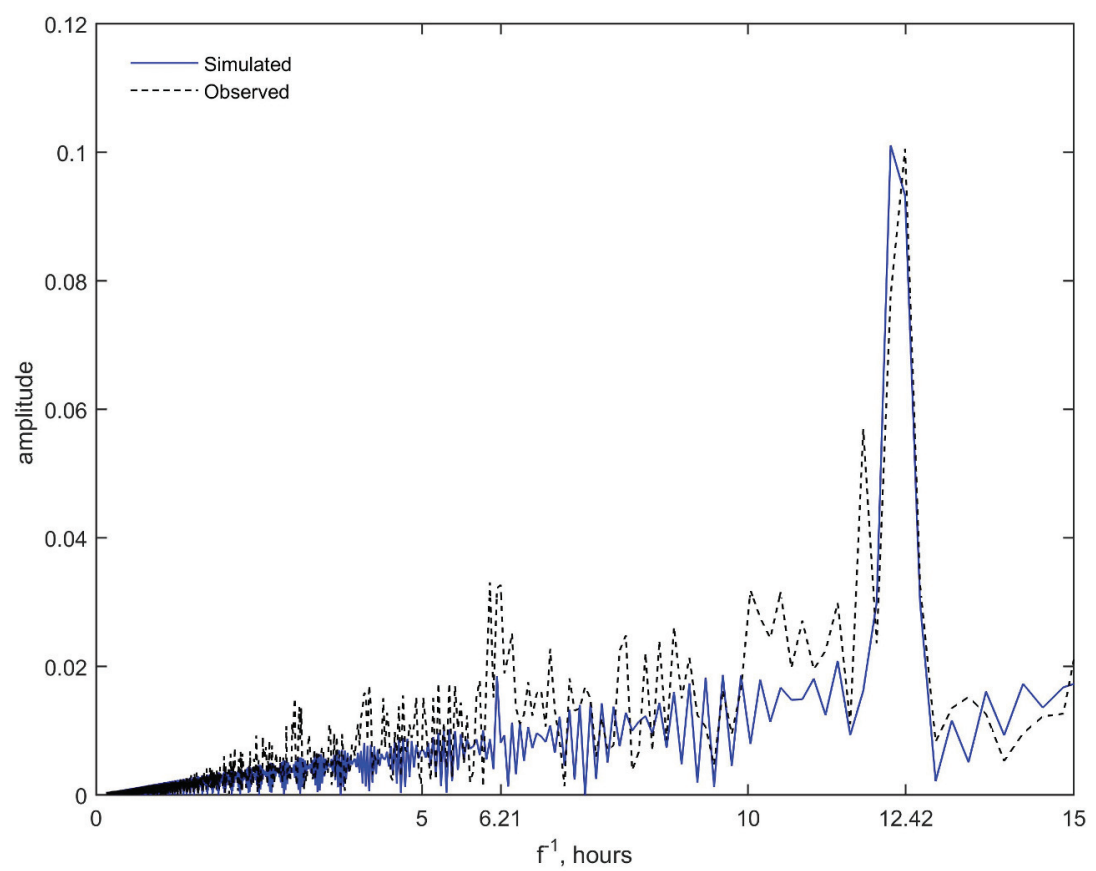

Figure 11: Observed and predicted (using the simplified method) tide-induced wave height ratios, $H_{s} / H_{s o}$, in the frequency domain, at the Pentland Firth site (Fig. 4). An excellent agreement is observed near the principal tidal constituent's period (i.e., M2 at $12.42 \mathrm{hr}$ ). 
(a) wave time series

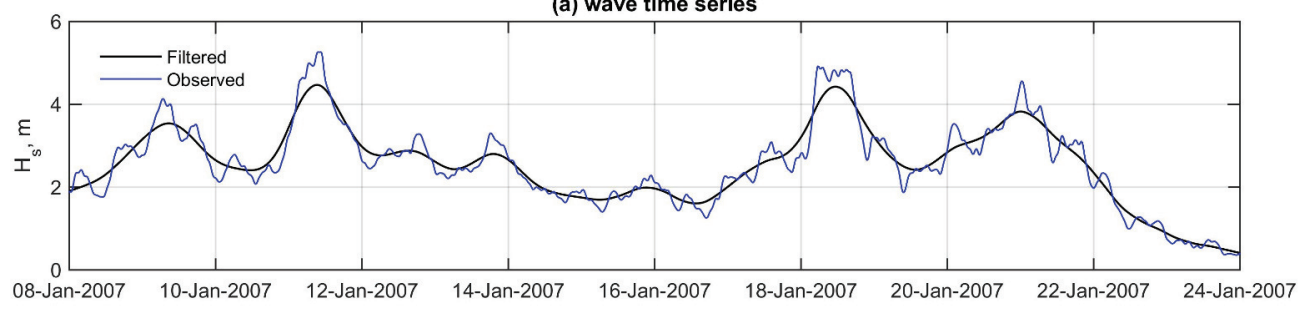

(b) tidal effect time series

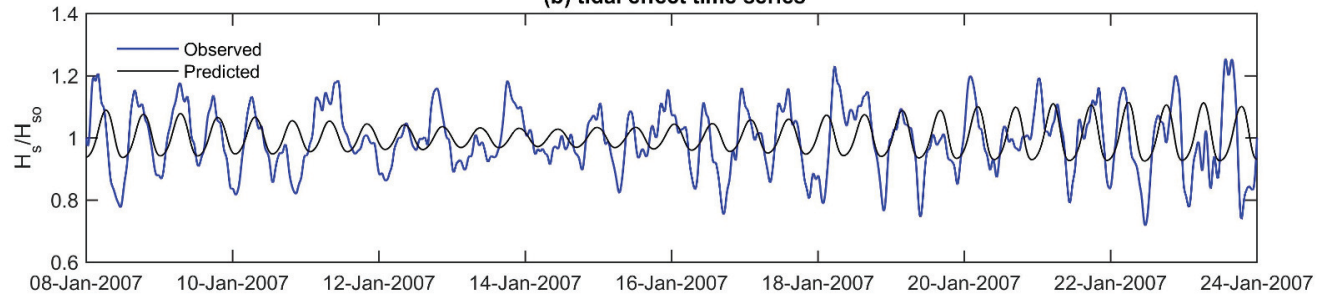

(c) tidal velocity

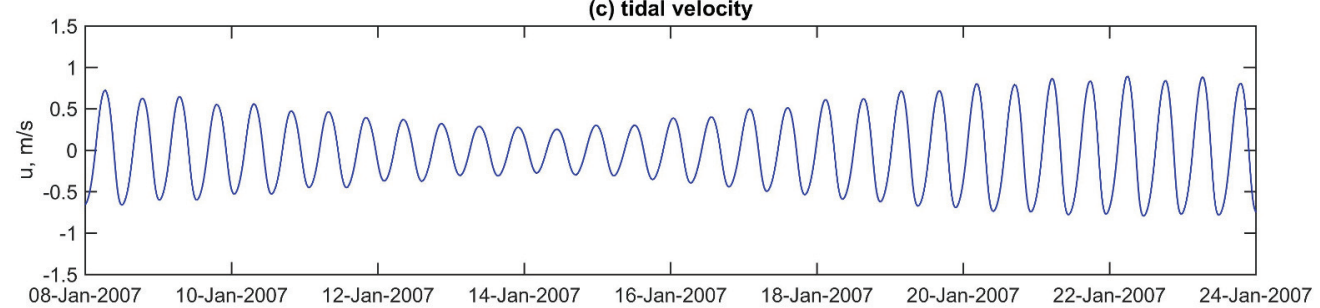

Figure 12: Application of the simplified method of estimating tidal current effects on waves to a time series of significant wave height observed at the Scarweather site (Fig. 4) during a spring-neap cycle. The tide-induced wave height modulations were filtered out from the signal (panel a), and the resulting wave height ratio compared with the predicted values (panel $b ; \mathrm{H} / \mathrm{H}_{\mathrm{o}}$ is the ratio of wave heights in the presence and absence of a tidal current computed from the two curves in panel a). The tidal current velocity estimated with ROMS is plotted in panel c. 


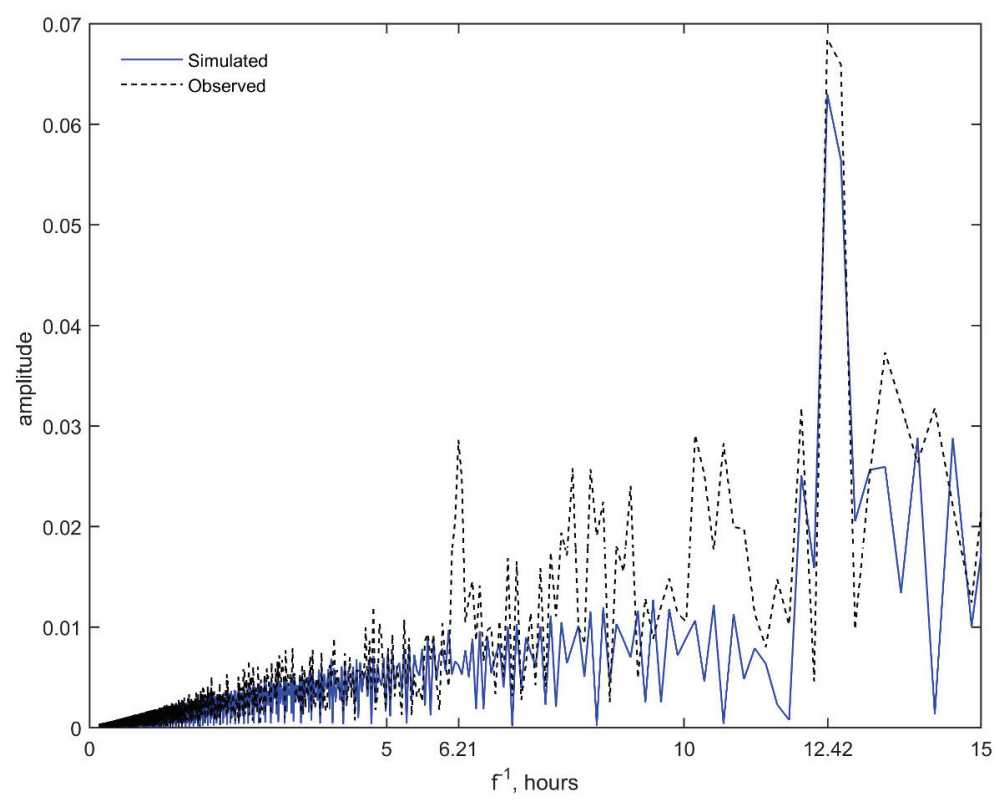

Figure 13: Observed and predicted (using the simplified method) tide-induced wave height ratios, $H_{s} / H_{s o}$, in the frequency domain, at the Scarweather site (Fig. 4). An excellent agreement is observed near the principal tidal constituent's period (i.e., M2 at $12.42 \mathrm{hr}$ ). 


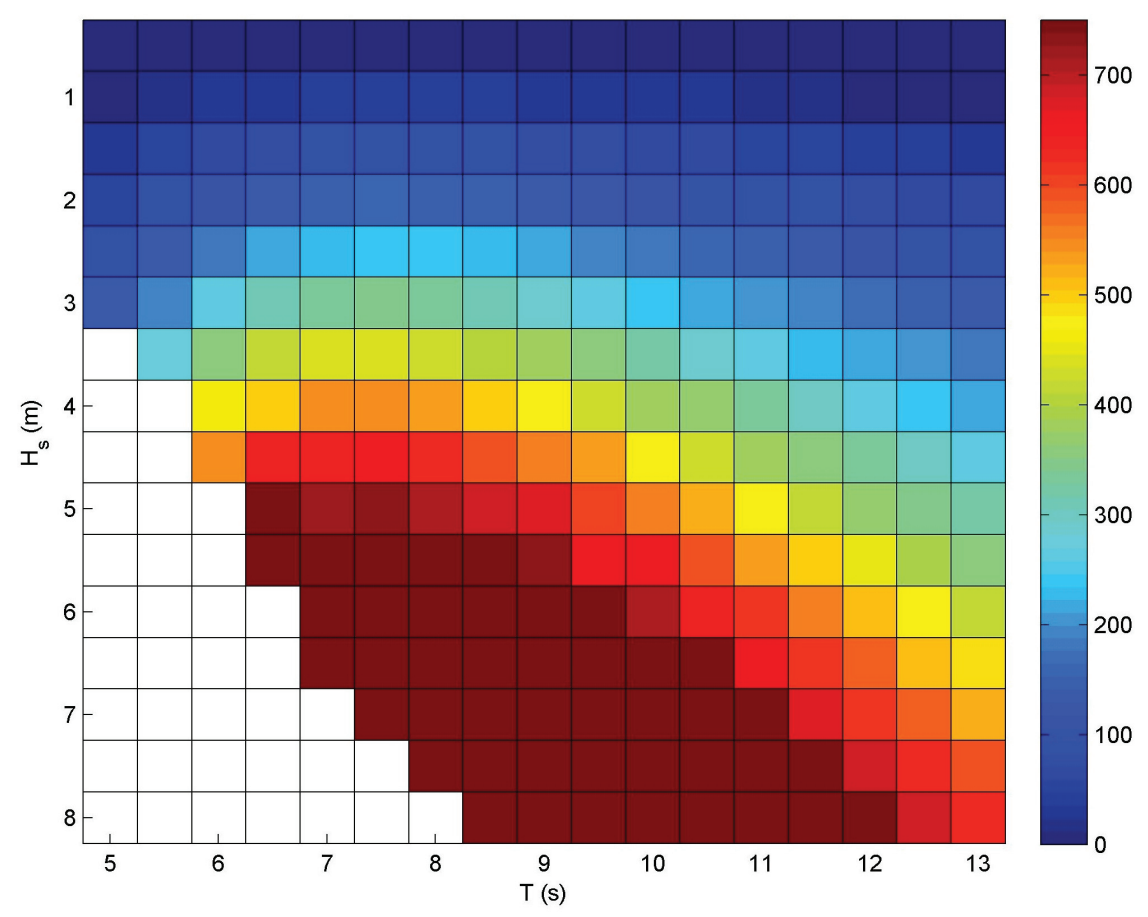

Figure 14: Power matrix of a Pelamis P2 [40] device rated at $750 \mathrm{~kW}$ as a function of significant wave height and period. The color scale is Power in $\mathrm{kW}$. 

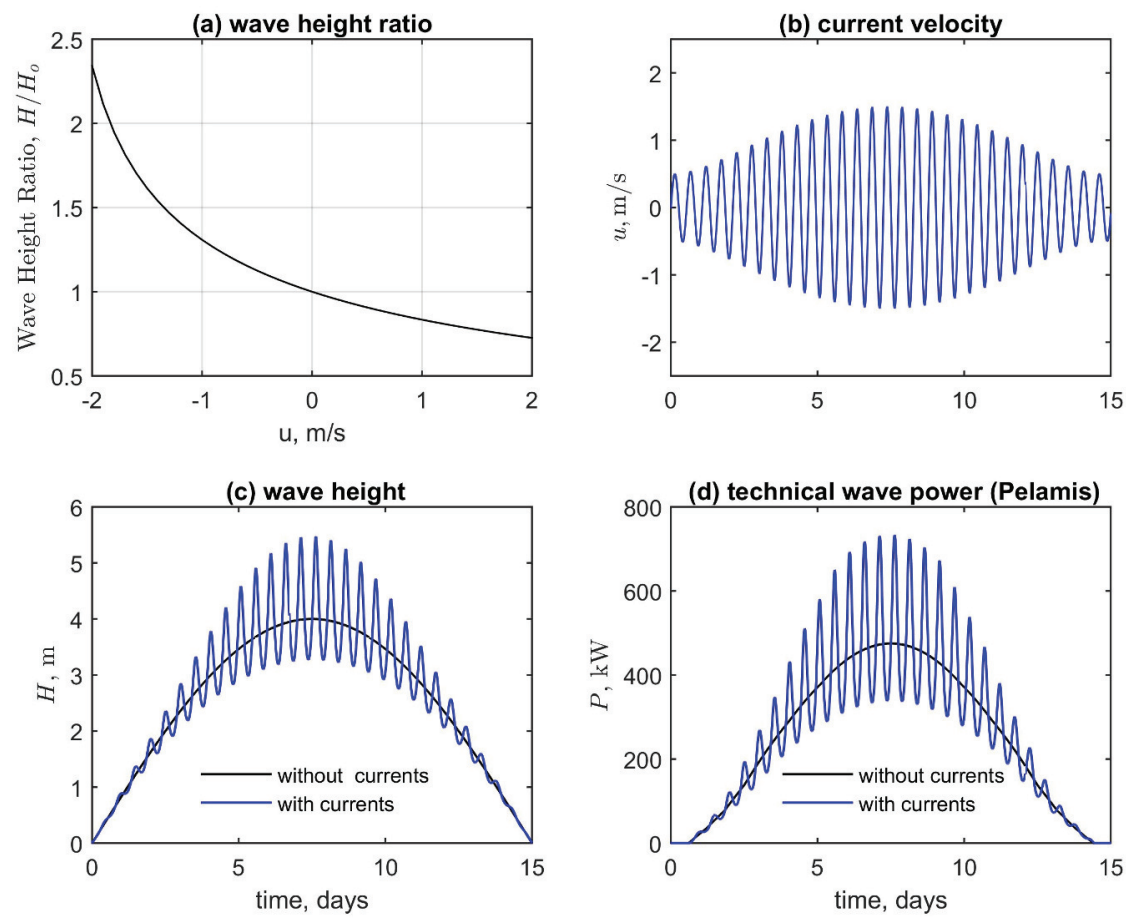

Figure 15: Asymmetric effects of tidal currents on the technical wave power for an idealized wave scenario. For a symmetric tidal current case (panel b), the overall effect is an increase in wave energy, from 89.9 MWh to 95.2 MWh, for the generated wave power depicted in panel d. 